ORNL/TM-2020/1811

CRADA/NFE-19-07910

\title{
CRADA Final Report: Open Microgrid Platform
}

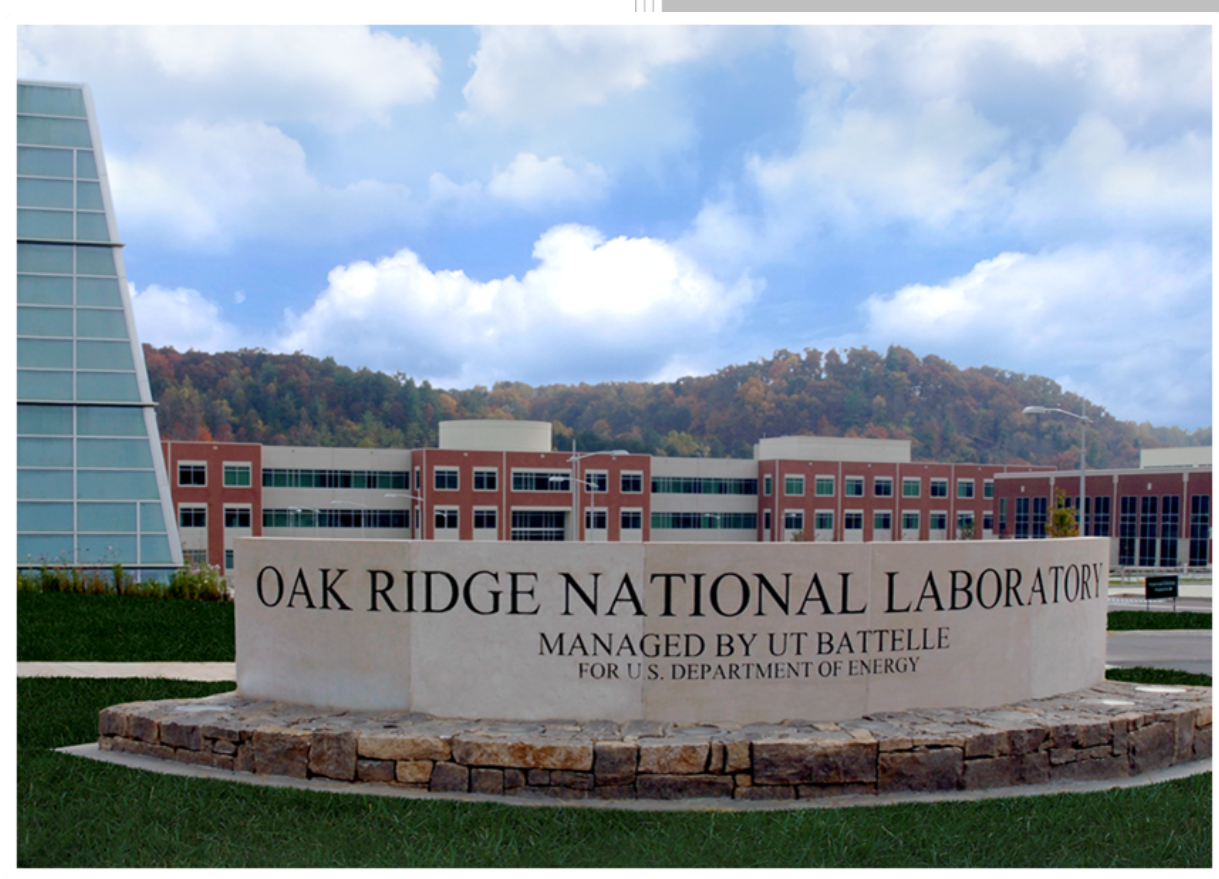

Ben Ollis

Andrew Herron

Patrick Brukiewa Joshua Hambrick

November 8, 2020 


\title{
DOCUMENT AVAILABILITY
}

Reports produced after January 1, 1996, are generally available free via US Department of Energy (DOE) SciTech Connect.

Website www.osti.gov

Reports produced before January 1, 1996, may be purchased by members of the public from the following source:

\author{
National Technical Information Service \\ 5285 Port Royal Road \\ Springfield, VA 22161 \\ Telephone 703-605-6000 (1-800-553-6847) \\ TDD 703-487-4639 \\ Fax 703-605-6900 \\ E-mail info@ntis.gov \\ Website http://classic.ntis.gov/
}

Reports are available to DOE employees, DOE contractors, Energy Technology Data Exchange representatives, and International Nuclear Information System representatives from the following source:

Office of Scientific and Technical Information

PO Box 62

Oak Ridge, TN 37831

Telephone 865-576-8401

Fax 865-576-5728

E-mail reports@osti.gov

Website http://www.osti.gov/contact.html

This report was prepared as an account of work sponsored by an agency of the United States Government. Neither the United States Government nor any agency thereof, nor any of their employees, makes any warranty, express or implied, or assumes any legal liability or responsibility for the accuracy, completeness, or usefulness of any information, apparatus, product, or process disclosed, or represents that its use would not infringe privately owned rights. Reference herein to any specific commercial product, process, or service by trade name, trademark, manufacturer, or otherwise, does not necessarily constitute or imply its endorsement, recommendation, or favoring by the United States Government or any agency thereof. The views and opinions of authors expressed herein do not necessarily state or reflect those of the United States Government or any agency thereof. 
ORNL/TM-2020/1811

CRADA/NFE-19-07910

Electrification and Energy Infrastructures Division

\title{
CRADA FINAL REPORT: OPEN MICROGRID PLATFORM
}

\author{
Ben Ollis \\ Andrew Herron \\ Patrick Brukiewa \\ Joshua Hambrick
}

November 8, 2020

Prepared by

OAK RIDGE NATIONAL LABORATORY

Oak Ridge, Tennessee 37831-6283

managed by

UT-BATTELLE, LLC

for the

US DEPARTMENT OF ENERGY

under contract DE-AC05-00OR22725 


\section{CONTENTS}

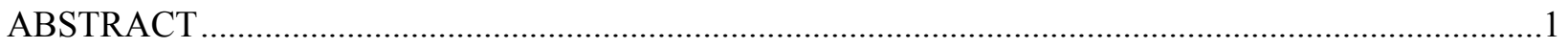

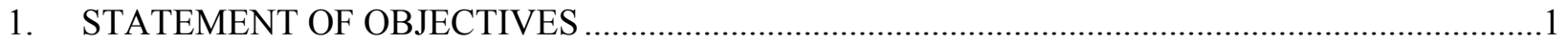

2. BENEFITS TO FUNDING THE DOE OFFICE'S MISSION ......................................................

3. TECHNICAL DISCUSSION OF WORK PERFORMED BY ALL PARTIES ...............................2

4. SUBJECT INVENTIONS (AS DEFINED IN THE CRADA) .....................................................

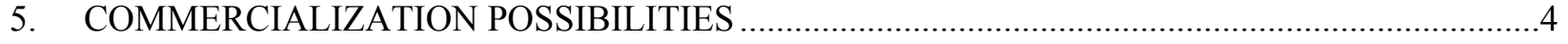

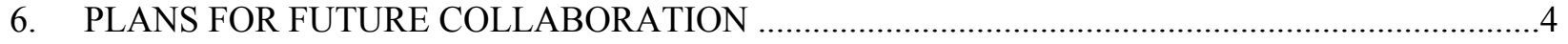

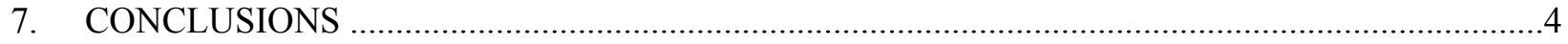




\begin{abstract}
Current microgrid control technology is mostly proprietary, expensive, and inflexible. An open-source, vendor-neutral, publish-subscribe controller will significantly lower the barrier to entry for new technologies and market entrants: inverter, battery, and load control manufacturers; cloud and services providers; and energy aggregators. An OpenFMB controller can significantly reduce the acquisition, integration, and ongoing operating and maintenance costs and increase revenue opportunities for energy producers and consumers. It allows distributed energy resource (DER) owners to replace individual DER components as richer-function, lower-cost devices become available or to incorporate new forecast and optimization algorithms as they are developed. A standard, secure, full-function DER field controller will also provide a low-cost means for grid operators to effectively manage the variability and uncertainty of solar photovoltaics (PV).

Under the terms of this CRADA, ORNL has worked with Open Energy Solutions (OES) to advance the transition of ORNL's existing open-source microgrid controller into a platform geared toward mainstream implementation. Using a more prevalent and memory-safe programming language, Rust, OES has converted ORNL's current generation on-grid optimization into an application more suitable for industry use. The results of the ported optimization were analyzed by inputting the same arguments in both the current-generation and next-generation optimizers and verifying that the results were equivalent.
\end{abstract}

\title{
1. STATEMENT OF OBJECTIVES
}

The following objectives were specified in the original CRADA:

- Task 1. Standards Applicability Research: Complete Month 3 (ORNL)

Research relevant standards (e.g., 2030.8 and 1547) for CSEISMIC conformance.

- Task 2. Initial Code Review and Documentation: Complete Month 6 (BOTH)

Perform initial code review and select collaboration platform (e.g., GitLab). Document current CSEISMIC architecture and functionality.

- Task 3. Use Case Documentation: Complete Month 6 (ORNL)

Document the use cases CSEISMIC will support and the methods by which those use cases are achieved.

- Task 4. New CSEISMIC Architecture Documentation: Complete Month 9 (OES)

Document changes required to the CSEISMIC architecture to support standards and use cases.

- Task 5. Evaluation of Architecture on ORNL Test Harness: Complete Month 12 (BOTH) Evaluate performance of initial CSEISMIC architecture on ORNL test harness, including reporting rate, measurement accuracy, and ease of implementation.

- Task 6. Open-Source Release: Complete Month 12 (BOTH)

Publish the CSEISMIC documentation and collaboration platform (code base, revision control, tests) on an open-source platform at the end of the agreement.

\section{BENEFITS TO THE FUNDING DOE OFFICE'S MISSION}

ORNL was uniquely capable of performing this research because the entire codebase of CSEISMIC was written and developed by ORNL staff. Significant investment has been made into the CSEISMIC 
platform by ORNL and DOE to develop the requirements, communications, and underlying algorithms to perform microgrid functions. No other organization has such intimate knowledge of how and why CSEISMIC was constructed. Furthermore, ORNL has developed CSEISMIC over years and has demonstrated its operation on multiple platforms, including real-time digital simulation, low-voltage hardware emulation, operational voltage ORNL microgrid, and a real-world microgrid in Southern Company territory.

Further development of the CSEISMIC platform will provide an open-source commercial version of microgrid controls to be used by academia and industry to advance the state of the art as well as provide an entry point for enhancing electrical system resiliency. This research will further ORNL's core capabilities in power systems and electrical engineering, as well as systems engineering and integration. Furthermore, with the ongoing work on the Citadels and COMMANDER (Coordinated Management of Microgrids and Networked Distributed Energy Resources) projects at ORNL, which consist of the creation of three $480 \mathrm{~V}$ networked microgrids with multiple distributed generation resources, ORNL will become an ideal testing facility for third-party industries to validate their modifications to the underlying open-source architecture.

Taking an open-source microgrid controller and making it more robust and commercial-grade provides opportunities for universities, utilities, and other laboratories to use the controller to further their research. This will reduce the barrier to entry into the microgrid space and hopefully speed the development of microgrid technologies to support the future grid. The new version of the controller will be used to run testbeds and field demonstrations more effectively, allowing for more in-depth research.

\section{TECHNICAL DISCUSSION OF WORK PERFORMED BY ALL PARTIES}

First, ORNL spent time reviewing applicable microgrid standards such as IEEE 1547 (interconnection of DERs) and IEEE 2030.8 (microgrid controller testing). The purpose of this task was to ensure that the code produced at the end of this project would remain compliant with grid standards so that it could continue to be used in the field. A list of minimum requirements for the controller was developed and included in background material provided to OES.

The initial code review and documentation exchange between ORNL and OES was a success. Multiple meetings occurred between stakeholders from both organizations, as well as frequent interactive presentations and question-and-answer sessions. In addition to the creation of functional documentation of CSEISMIC's current architecture (see Figure 1), decision trees, future proofing, and corner cases were presented, as well as a multitude of lessons learned during commissioning of the Southern Company microgrid. Meetings were continued on at least a biweekly basis all the way through completion of Task 6 to transfer as much knowledge as possible between the two parties. 


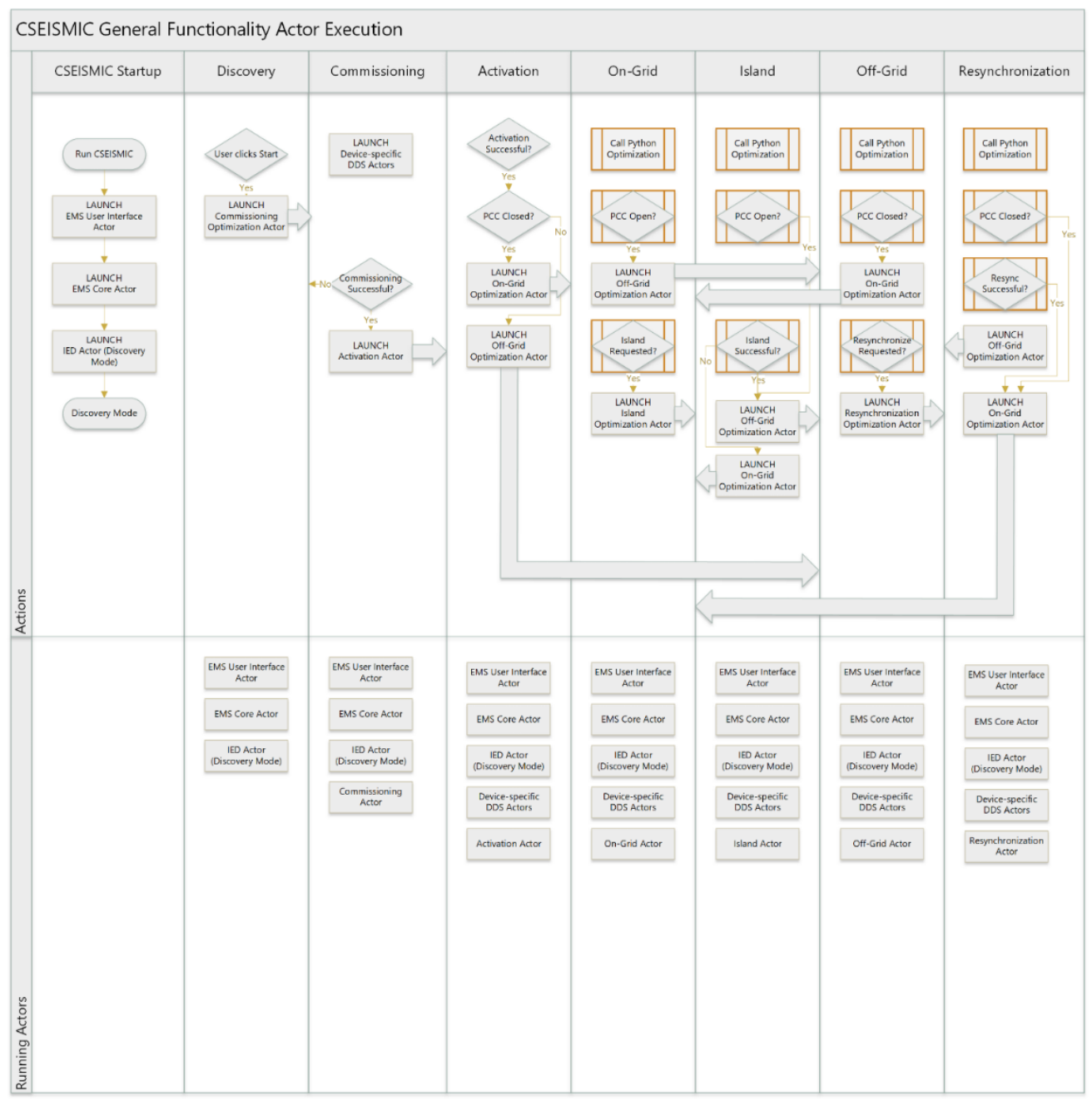

Figure 1. Example documentation generated during CRADA.

Use cases were discussed and various optimization schemes were presented that demonstrated cases relevant to price and stability optimization, PV smoothing, and power factor control. Although the main focus of the work was on price and stability optimization, the interface between CSEISMIC and external optimizations was discussed at length to provide entry points for future testing of additional use cases. Data sets for inputs and outputs of known states were exchanged to document the structure of parameters and results across all use cases.

In conjunction with the documentation and review about support of current use cases, new use cases were discussed. Specifically, future support of networked microgrids and non-radial buses was discussed. Limitations to the current design, as well as necessary modifications, were debated between the stakeholders and some potential avenues for advancement in these areas were ideated.

Because of the COVID-19 pandemic and the subsequent work-from-home orders, evaluation of the new generation of the on-grid optimization on ORNL's systems was not feasible. However, OES developed a test harness to validate conformance of the new on-grid optimization with ORNL's existing current generation.

A repository for sharing the open-source work generated during the CRADA has been hosted on ORNL's external facing git server, with plans to migrate future work to a more popular service such as GitHub or 
BitBucket. Although documentation has been added to the repository, a more cohesive format that encompasses all relevant documentation will be implemented in the future to facilitate more effective knowledge transfer to new project contributors.

\section{SUBJECT INVENTIONS (AS DEFINED IN THE CRADA)}

None.

\section{COMMERCIALIZATION POSSIBILITIES}

Although the final work product of this CRADA was an open-source software package, a multitude of future commercialization opportunities exist. The new microgrid controller software was intentionally designed with a modular approach that allows each section of the code to be a self-contained package (e.g., historian, optimization, forecasting, SCADA interface). Because the inter-package communication is based on publish-subscribe Transmission Control Protocol communication instead of applicationspecific inter-process communication, a module can be replaced, removed, or added to the overall controller offering without requiring modification of any of the other existing modules.

For example, if ORNL developed a new cutting-edge optimization that decreased the time required to solve and increased the effectiveness of the optimization, it could be offered as a standalone package meant as a drop-in replacement for the existing optimization module. Third-party integrators could write utility-specific SCADA interface packages and historians, as well as add support for additional use cases using their own optimization packages. Moreover, integration of the open-source framework at a utility's site could be a lucrative opportunity, in addition to integrating third-party packages on ORNL's new COMMANDER system to perform validation testing as a service for third parties.

\section{PLANS FOR FUTURE COLLABORATION}

ORNL plans to continue to work with OES to advance the art of the new microgrid controller for deployment on the COMMANDER system and for testing with the Citadels Grid Modernization Laboratory Consortium project. OES hopes to implement the optimization and controller in its own OpenDSP platform, which exists one application layer higher than the new controller. Working with OES to embed the new functionality in its own open-source platform furthers ORNL's goals to drive adoption of the controller framework and create opportunities for additional research in the future. ORNL will continue to work with OES on other funded work, such as the Citadels Grid Modernization Laboratory Consortium project while pursuing future funding opportunities to further expand the capabilities of CSEISMIC as a research controller.

\section{CONCLUSIONS}

ORNL and OES had a very productive working arrangement throughout the duration of the CRADA. The amount of knowledge-sharing between the two organizations was beneficial to all, and the work produced by the end of the CRADA significantly helps to advance the goal of providing a complete commercialgrade open-source microgrid controller. Best practices on collaborative development were explored and will assist in maintaining the productivity and momentum of future work between the two organizations. Moreover, the work completed during the CRADA will serve as an effective building block upon which both organizations can continue related development that will build upon the consensus-driven framework that has been established. 